\title{
PELE: AMAZONAS TATUADAS
}

Adrienne Mayor ${ }^{1}$

A jovem mulher está segurando um machado, prestes a cortar a cabeça de Orfeu, o poeta que foi morto por impiedosas mulheres trácias no mito grego. Os olhos do observador são atraídos para delicada tatuagem de cervo em seu ombro. Outra tatuagem enfeita o interior de seu antebraço, um desenho de escada. A imagem aparece num vaso grego atribuído ao Pintor de Pistóxenos, que pintou trinta e oito vasos com mulheres trácias tatuadas (480-470 a.C.). Seu nome significa "Estrangeiro Confiável" talvez ele próprio fosse um trácio. ${ }^{2}$ (Harrison, 1888: 16).

Devido aos escritores gregos terem descrito mulheres e homens trácios como tatuados, estudiosos clássicos identificam todas as mulheres tatuadas em vasos gregos como "trácias" ou quaisquer outras estrangeiras. ${ }^{3}$ Mulheres trácias não eram amazonas, mas compartilhavam diversos traços importantes com mulheres guerreiras citas conhecidas como amazonas: elas eram independentes, violentas assassinas de homens empunhadas de armas mortais, e frequentemente vestidas em trajes semelhantes. Os gregos, que tatuavam somente criminosos e presos de guerra com marcas de vergonha, conheciam diversos outros povos, além dos trácios, que praticavam tatuagens voluntárias com símbolos atrativos. As mulheres citas eram conhecidas por serem tatuadas? Os gregos viam amazonas com tatuagens? Há pistas de tatuagens que foram esquecidas em pinturas de vasos? O que podemos aprender das tradições modernas de tatuagens? Quais evidências arqueológicas existem sobre tatuagem?

\footnotetext{
${ }^{1}$ Skin: tattooed Amazons. In: Adrienne Mayor. The Amazons. Lives \& Legends of Warrior Women across the Ancient World. Pincetono and Oxford: Princeton University Press, p. 95-116.

2 Taça branco-terra, Pintor de Pistóxenos, Museu Nacional de Atenas, Acrópoles 439. Zimmermann 1980. Cohen 2000, 113, fig 4.4.

3 "Mulheres tatuadas em vasos atenienses são certamente trácias": Oakley 2000, 242. Tattoos in antiquity, Mayor 1999; Lobell and Powell 2013.
} 


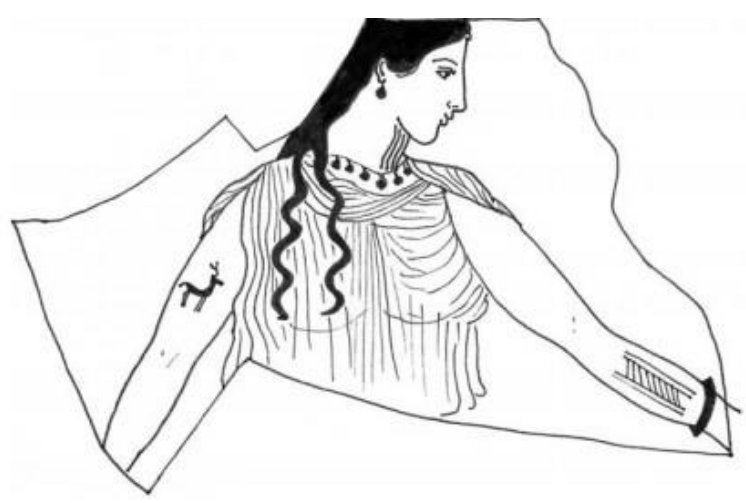

Figura 1: Mulher trácia com machado; tatuagem de cervo em seu ombro direito; tatuagem de "escada" em seu pulso esquerdo. Taça em terra branca, Pintor de Pistóxenos, ca. 460 a.C., Museu Arqueológico Nacional de Atenas Inv. no. Akr. 439. Desenhado posteriormente por Harrison 1888, pl.6.

Intrigantes partes de evidências na arte e na literatura, etnologia e arqueologia clássicas se combinam para fazer tais perguntas valerem a pena.

\section{Trácios, citas e amazonas}

"Trácios", assim como nome inclusivo "citas", referem-se às diversas tribos em comum que habitaram o território que se estende do Mar Negro ao Mar Adriático (norte da Grécia, Turquia europeia, sudoeste da Ucrânia, Romênia, Bulgária, Albânia, e a antiga Iugoslávia). Os territórios da Trácia e da Cítia coexistiram e, desde ao menos 700 a.C., os trácios se agregaram pacífica e violentamente aos citas. A arqueologia demonstra laços culturais trácios-citas. Foram encontrados não somente bens trácios em sepulturas citas, e artefatos citas em sepulturas trácias em 560-450 a.C., como restos mortais de mulheres guerreiras foram escavados na antiga Trácia (capítulo 4). Trácios e citas foram vizinhos e parentes através de conquistas e casamentos mistos. Muitos de seus costumes se fundiram. Diversas tribos trácias-citas, como as de Tyragetai e Agathyrsi, foram narradas por Heródoto e Estrabão. De acordo com Estrabão, os Bithynians, Phryians, Mysians, Mygdonians, e os Troianos foram todos de origem trácia, e uma tribo trácia, os Saraparai ("Decapitadores"), foram mencionados por terem migrado para o extremo leste, além da Armênia até os estepes citas ${ }^{4}$.

Os trácios, os citas e as amazonas compartilhavam um estilo de luta guerrilheira com infantaria (os peltastas), arqueiros e cavalaria, e suas roupas, armas, equipamentos, e temas artísticos eram similares. Colonos

${ }^{4}$ Cultura compartilhada trácia-cita: Marazov 2011a e b. Farkas 1982. Dowden 1997, 99.
Homero Ilíada 2.819. Heródoto 4.104; 4.119; 4.125; 4.48. Estrabão 7.3.2-5; 11.14.14; 12.3-4.

Heródoto, Unifesp, Guarulhos, v.4, n.1 - 2019.1. p. 305-326

DOI: 10.34024/herodoto.2019.v4.10126 
gregos guerrearam com trácios autóctones do sétimo ao sexto século a.C. Uma taça em figuras negras (cerca de 560 a.C., acredita-se pertencer à uma tumba trácia), une gregos, trácios e amazonas de uma forma interessante. $\mathrm{O}$ exterior da taça mostra uma batalha "quasi-histórica" entre gregos e trácios, enquanto no interior, o herói grego Héracles guerreia com uma amazona. A cena mítica parece igualar a amazona aos trácios. ${ }^{5}$

Por volta de 550 a.C., pintores de vasos gregos passaram a retratar amazonas com uma combinação de roupas e equipamentos entre trácios e citas, coincidindo com o aumento da familiaridade dos gregos com estas duas raças de guerreiros, e com a miscigenação dos dois povos em processo nas margens de seus territórios. ( $\mathrm{Na}$ arte antiga, as amazonas eram imaginadas como mulheres gregas hoplitas, com curtos quítons, armadura, capacete, escudo redondo e lança). Conforme a popularidade das cenas amazonas aumentava e a familiaridade crescia, artistas passaram a demonstrar Hipólita, Antíope, Pentesileia e outras amazonas com aljavas, arcos, dardos, vestidas em túnicas e calças estampadas, botas e chapéus pontiagudos, típicos trajes trácios e citas (e, mais tarde, persas). Em 525 a.C., diversas amazonas foram retratadas com o pelta, um escudo trácio feito de vime em meia lua, e algumas vestiam uma distinta manta trácia (zeira). Pinturas em vasos também retratavam amazonas vestindo peles malhadas de leopardo, acessório símbolo das Mênades trácias (violentas seguidoras de Dionísio, em alguns mitos foram elas quem mataram Orfeu). ${ }^{6}$

Os trácios, citas e as amazonas eram povos cavaleiros. Uma amazona cavaleira pintada por Polignoto é chamada de Dólope, o nome de uma tribo trácia. Os trácios foram descritos pelos gregos como altos, de cabelos lisos e avermelhados, com a pele clara e tatuada. Os trácios, citas e os persas eram frequentemente retratados como ruivos nos vasos. A equiparação artística de amazonas com trácios conduz alguns estudiosos a assumir que os pintores dos vasos, e seus observadores, conheciam tradições orais genuinamente antigas que localizavam as amazonas na Trácia. De fato, uma das mais antigas menções às amazonas nos escritos gregos as situam na Trácia. De acordo com o épico de Aethiopis, (século VII a.C.) as amazonas eram uma raça trácia e Pentesileia, a rainha

\footnotetext{
5 Trácias e amazonas: Blok 1995, 265-76. Tsiafakis 2000. Shapiro 1983, 110, Taça Siana, Berlin Antikensammlungen 3402.

6 "Amazonas trácias", Shapiro 1983, 107-14; peles de leopardo e filhote de cervo, 108. Blok 1995, zeira e amazonas, 399 (Bothmer B IX 41 e 45), 405; e calças amazonas com zeira, alabastro branco-terra, Museu Nacional de Atenas. Cita ruiva, Pintor de Berlin, Malibu, Getty 96. AE. 98.
}

Heródoto, Unifesp, Guarulhos, v.4, n.1 - 2019.1. p. 305-326

DOI: 10.34024/herodoto.2019.v4.10126 
amazona que teve papel primordial na Guerra de Tróia, nasceu na Trácia. Em Ilíada, de Homero, trácios e amazonas eram ambos aliados de Tróia (ver fig. 8.2 para uma pintura em vaso de uma caçadora trácia oferecendo um presente à Petensileia).

De acordo com o historiador grego Hecateu de Mileto (550-476 a.C.), as amazonas de Ponto falavam um dialeto trácio. Estrabão relata uma velha história sobre trácios se unindo aos gargareanos do norte do Cáucaso para guerrear com as amazonas (capítulo 8). Diodóro descreve uma guerra contra as amazonas travada por um exército trácio-cita liderado pelo trácio Mopsus e pelo cita Sipylus. Diversas fontes antigas afirmam que vários grupos na Ásia Menor eram originários da Trácia. Os fortes laços culturais e a proximidade geográfica de trácios, citas e amazonas sugerem que tais grupos compartilhavam diversos costumes, incluindo a tatuagem. ${ }^{7}$

\section{Tatuagens em pinturas de vasos gregos}

Diversos outros pintores atenienses além do "Estrangeiro Confiável" se encantaram em representar atraentes mulheres trácias tatuadas atacando Orfeu, além de jovens e velhas escravas estrangeiras tatuadas em cenas domésticas. Braços e pernas (e às vezes rostos e pescoços) das escravas são decorados com ziguezagues, chevrons, "escadas", "cercas", linhas onduladas, raios de sol, círculos, espirais, rosetas e cervos.

Um vaso em figuras vermelhas de 500-450 a.C. mostra duas robustas corredoras com braços e pernas excessivamente tatuados. Seus cabelos ruivos e soltos as associam com trácias ou citas (Orfeu não aparece na pintura). Uma delas possuí linhas onduladas em seus tornozelos e braços estendidos. A outra caminha a passos largos com uma espada. Cervos estão tatuados em cada um de seus combros e em suas pernas, juntamente com ziguezagues, raios de sol e pontos que continuam até suas mãos e pés (fig. 6.2). Outro fragmento de cratera (século IV a.C.) retrata um grupo de furiosas mulheres descalças e calçadas com roupas em estilo trácio-cita-amazonas. Seus braços e pernas estão completamente cobertos com raios de sol, linhas geométricas, e figuras de cobra e cervo. ${ }^{8}$

\footnotetext{
7 Shapiro 1983, Aethiopis, Proklos Chrestomathia 2 (p 105 Allen). Hecateu FGrHist 802 F 3: Vlassopoulos 2013, 183; Blok 1995, 153; e Braund 2010, 17. Estrabão 7.3.2-13 11.5.14; Herodoto 7.73; Diodoro 3.55.10-12.

8 Tatuagens de mulheres trácias em vasos, discutidas e ilustradas em Zimmermann 1980. Tsiafakis 2000, 372-76, figs 14.4 e 14.5; Oakley 2000, 242-44, figs 9.9 e 9.10. Berard 2000, 391-92, fig 15.1. Cohen 2000, 99, figs 4.2 e 4.4. Duas mulheres tatuadas corredoras, colunas em crater, Pintor de Pan, 470 a.C., Munich Staatliche Antikensammlungen 2378 (J. 777). Amazonas trácias, Blok 1995, 259-76.
}

Heródoto, Unifesp, Guarulhos, v.4, n.1 - 2019.1. p. 305-326

DOI: 10.34024/herodoto.2019.v4.10126 


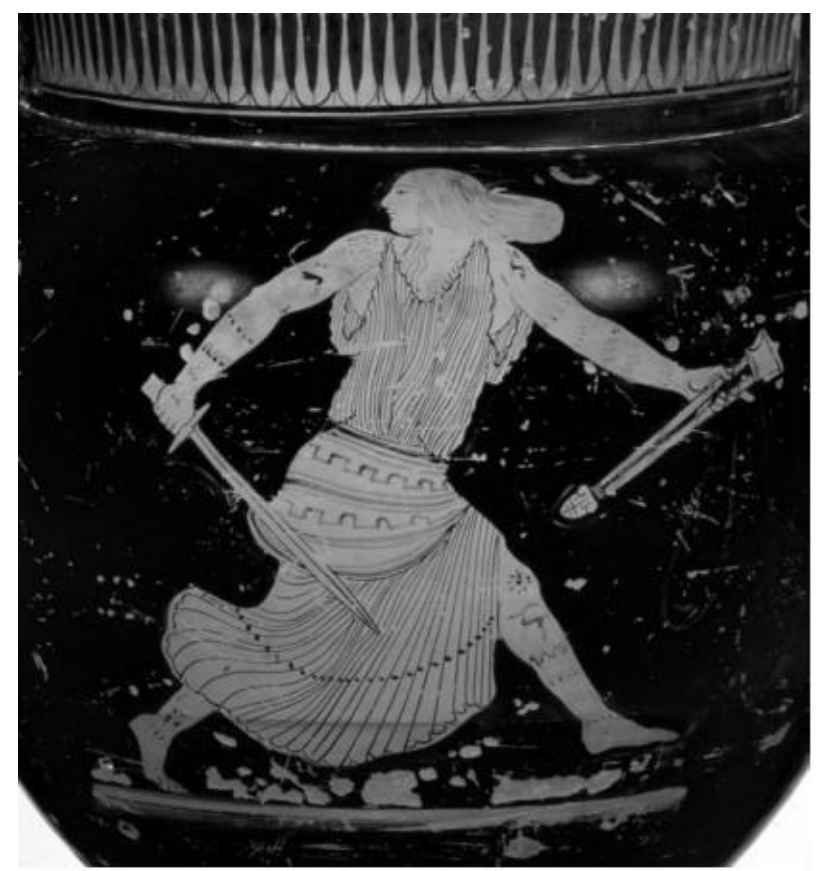

Figura 2: Mulher trácia ruiva correndo com uma espada e uma bainha; seus braços e pernas estão tatuados com cervo, raios de sol, pontos e linhas onduladas. cratera com colunas em figuras vermelhas, Pintor de Pistóxenos, Ática, Grécia, ca. 480-450 a.C., inv. 2378. Fotografia por Renate Kühling, Staatliche Antikensammlungen und Glyptothek, Munique.

Outro elegante exemplo de mulheres trácias tatuadas aparece gravado numa taça de prata descoberta em 2007, no oeste da Bulgária, numa tumba trácia real do quinto século a.C. A taça foi feita no mesmo período que as pinturas de mulheres trácias tatuadas nos vasos atenienses. A bela e severa mulher trácia atacando Orfeu com um machado possuí tatuagens envolvendo seus pulsos e tornozelos, e sete pontudas estrelas adornam seus braços superiores. ${ }^{9}$

\footnotetext{
${ }^{9}$ Tatuagens trácias: Saporiti 2009, Tsiafakis 2000. Tatuagens trácias em taças de prata: Marazov 2011b, 170-73, fig 5.24a-b; 2011a, 56-58, 78-79. Tatuagens retratadas em artefatos trácios: Frkas 1982, 43-45. Em contraste, uma ânfora de figuras vermelhas (550 a.C. Vienna 3722) mostra uma feia estrangeira marcada como "Injustiça" sendo atingida pela deusa grega da Justiça. A bruxa bárbara está coberta de tatuagens circulares que lembram algumas tatuagens em mulheres trácias, assim como desenhos nas roupas das amazonas. Os mesmos círculos e pontos marcam as asas, braços e as pernas de uma dupla de feias mulheres bárbaras personificando Poena (400 a.C., Pintor de Policoro, Museu de Arte de Cleveland). Mas os mesmos desenhos circulares cobrem o macacão colado ao corpo e as mangas das belas amazonas do Pintor de Eretria, 420 a.C., centro e extrema direita, fig. 13.6.
}

Heródoto, Unifesp, Guarulhos, v.4, n.1 - 2019.1. p. 305-326

DOI: 10.34024/herodoto.2019.v4.10126 

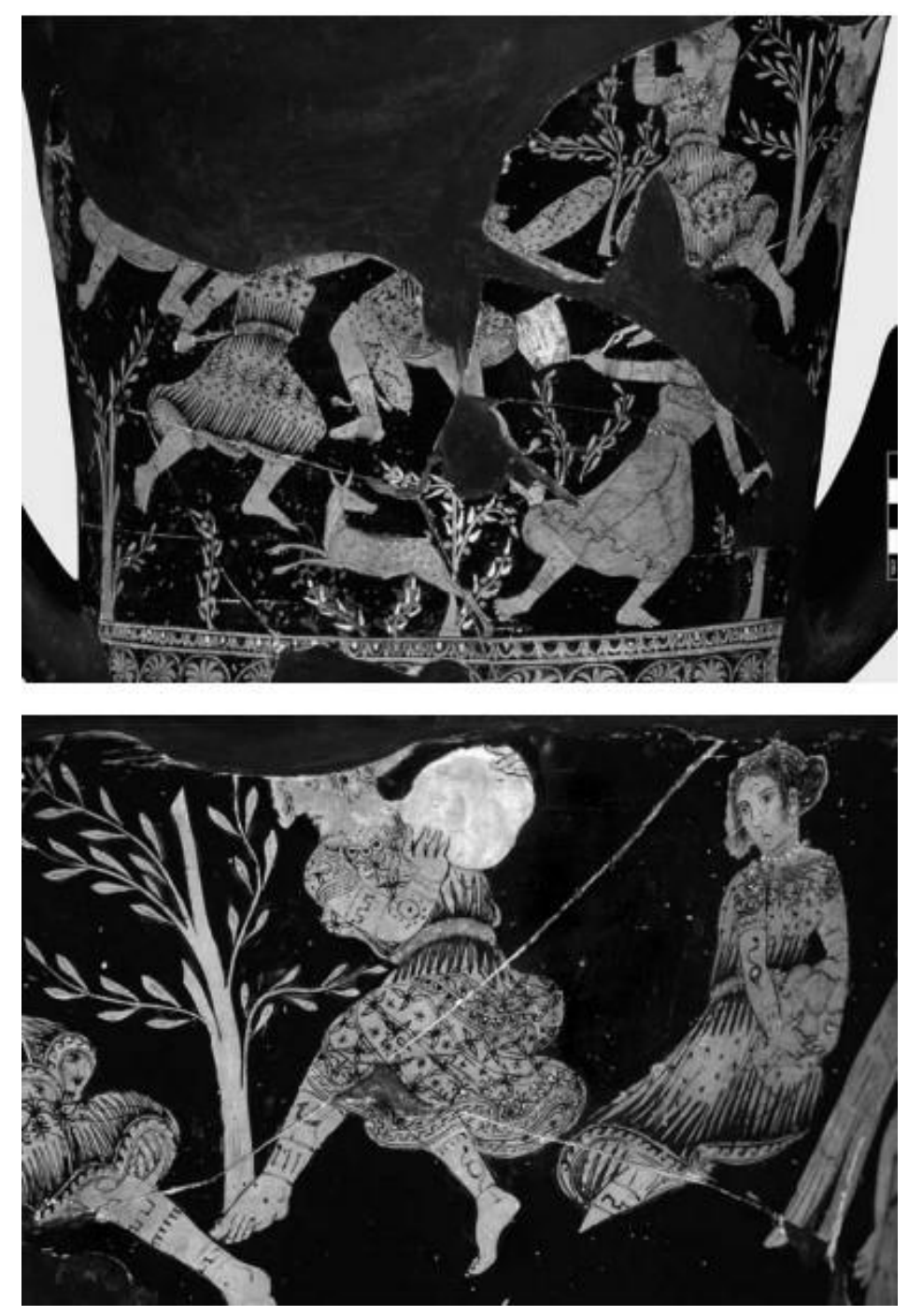

Figura 3: Grupo de mulheres trácias demasiadamente tatuadas com cervos, cobras e desenhos geométricos. Cratera em cálice em figuras vermelhas, Black Fury Group, ca. 470 a.C. Cortesia do Museu Allard Pierson, Amsterdã, Inv. APM 02581.

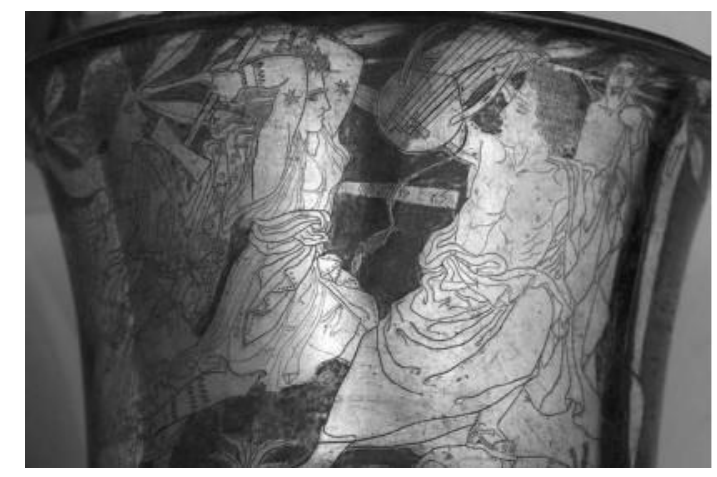

Figura 4: Mulher trácia atacando Orfeu com um machado; seus braços (e pernas, única à mostra) estão tatuados com estrelas e desenhos de pulseiras e tornozeleira. Taça de prata (katharos), quinto século a.C., Coleção Vassil Bojkov, Bulgária. Cortesia de Ivan Marazov.

Heródoto, Unifesp, Guarulhos, v.4, n.1 - 2019.1. p. 305-326

DOI: 10.34024/herodoto.2019.v4.10126 
Padrões geométricos e temas de animais semelhantes às tatuagens de mulheres trácias, e à de outras mulheres estrangeiras começaram a aparecer em roupas de amazonas de estilo cita (às vezes chamadas de estilo "do leste" ou "oriental") em pinturas de vasos de meados do século sexto a.C. Um dos primeiros exemplos de figuras de animais bordados, ou aplicados, na frente de uma túnica aparece numa ânfora em figuras negras (570-560 a.C.) retratando uma amazona chamada Andrômaca, lutando com Héracles. A roupa de Andrômaca está esplendidamente ornamentada com fantásticos grifos, pássaros e felinos. Uma amazona chamada Kydoime, em um vaso de Eufrônio (520-40 a.C.), veste um dispositivo com leões na aba dos ombros de seu corselet. ${ }^{10}$ (Shapiro, 1983: 106) Em outras pinturas, as amazonas vestem longas mangas e calças justas ricamente decoradas. Nas mulheres trácias e nas escravas estrangeiras, desenhos são claramente retratados como gravações na pele nua, enquanto os padrões selvagens de braços e pernas das amazonas representam roupas coladas ao corpo com desenhos que se assemelham à tatuagens. Assim como nas pessoas reais, a dinâmica das tatuagens nos corpos trácios e os vívidos padrões nas roupas das amazonas acentuam seus músculos e movimentos, chamando atenção para força, atletismo e sexualidade das mulheres.

Com algumas pinturas deve-se olhar de perto para dizer se as linhas onduladas, os ziguezagues, os círculos e os animais estão na pele ou na roupa. As tatuagens das mulheres trácias param nos tornozelos e nos pulsos, dando uma aparência de longas mangas e leggings. Na maioria das figuras amazonas, linhas pintadas no pulso e no tornozelo indicam punhos ou bordas de mangas ou calças. Mas alguns padrões dos braços e pernas das amazonas são tão parecidos com tatuagens que o observador faz duas percepções (prato 12, figs. 6.5, 13.6, 13.8).

Os braços e pernas das mulheres trácias nas figuras 2, 3 e 4 estão tatuados com cervos, cobras e desenhos geométricos; as linhas nos pulsos e tornozelos dão a aparência de pulseiras ou punhos. O efeito visual oscila entre uma espécie de meia estampada com desenhos e marcas impressas na pele. Ilusões de óticas provocando efeitos visuais e alusões para outras imagens artísticas muito bem conhecidas são truques comuns do comércio de vasos atenienses. As tradições modernas de tatuagem costumam brincar com a mesma ambiguidade: tatuagens no corpo inteiro e "mangas" se assemelham a roupas, e alguns topes e meias justas deliberadamente imitam tatuagens.

\footnotetext{
${ }^{10}$ Vestido da Andrômaca com grifos, pássaros, leões: ânfora de figuras negras assinada pelo Pintor de Timíades, entre 570 e 560 a.C., Museu de Belas Artes de Boston 98.916. Leão no colete de Kydoime, Bothmer 1957, 136.
}

Heródoto, Unifesp, Guarulhos, v.4, n.1 - 2019.1. p. 305-326

DOI: 10.34024/herodoto.2019.v4.10126 
Mangas, golas, pulseiras e tornozeleiras tatuadas que imitam bordas de roupas são desenhos tradicionais em diversas culturas de tatuagens. Nos Balcãs, por exemplo, etnógrafos antigos observaram que camponesas continuavam a tatuar seus braços com desenhos tradicionais reminiscentes das tatuagens trácias na arte grega - raios de sol e de meias luas, rosetas, espirais, hachuras em escada e cercas. O que antes era visto como longas e bordadas luvas em imagens de mulheres da Daunia, esculpidas em estelas de pedra no sul da Itália, agora são pensadas para representar tatuagens no antebraço. A Daunia foi colonizada por Ilírios do oeste da Trácia, que eram conhecidos por praticar a tatuagem. ${ }^{11}$ (Truhelka 1986: 500)

Muitas pinturas de vasos são impressionantes, e a "ambiguidade" de algumas linhas nos pulsos e tornozelos das amazonas pode resultar de pinturas apressadas e desleixadas. A semelhança das tatuagens e dos vestuários pode refletir o repertório artístico padrão de desenhos selvagens para indicar os "outros" bárbaros. Talvez alguns artistas deliberadamente pintavam linhas que pudessem ser tanto colares, mangas e punhos - ou tatuagens, incentivando os observadores a comparar os padrões em figuras amazonas às tatuagens trácias.

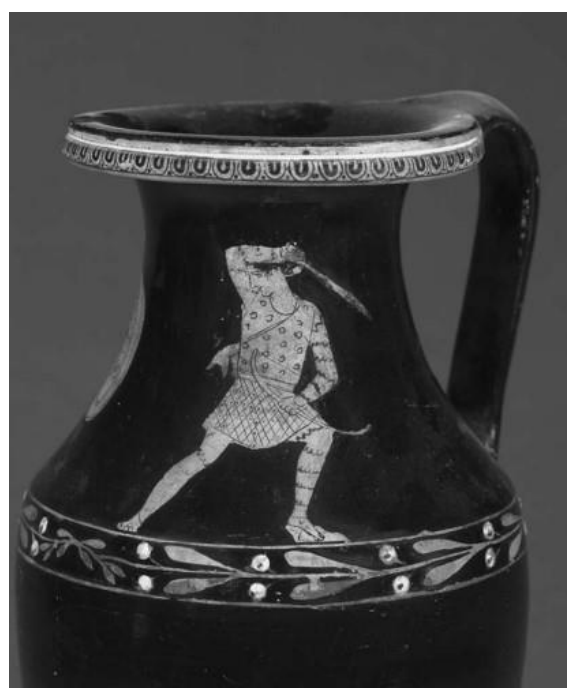

Figura 5: Amazona descalça com mangas e leggings que parecem tatuagens, com arco, aljava e espada. Olpe (jarro) de figuras vermelhas, Pintor do Louvre, sexto século a.C., Inv. G443, Museu do Louvre, Paris. Foto: Hervé Lewandowisk. (C) RMN-Grand Palais/Art Resource, NY.

Pintores de vasos costumavam provocar seus espectadores entrelaçando mitos com realidades sociais, de fato. No sexto século a.C., os atenienses

\footnotetext{
${ }^{11}$ Durham 1928. Os daunios da Apúlia tinham origens ilíricas: Norman em Della Casa e Witt 2013.
} 
eram extremamente familiarizados em avistar estrangeiros tatuados em suas cidades e lares. Explorando a ambiguidade artística sobre as tatuagens está a ideia de que as amazonas eram ousadas e livres, e não escravas.

\section{Tatuagens em textos antigos gregos, latinos e chineses}

Além dos trácios, os gregos encontraram diversas outras pessoas tatuadas entre seus vizinhos do Mar Negro e de Ponto, as maiores fortalezas amazonas. Numerosos autores relataram tatuagens entre citas. Hipócrates, por exemplo, observou que nômades citas "marcavam" figuras em seus ombros, braços, peitos e coxas para "incentivar a força e a coragem", sugerindo uma função mágica das tatuagens. Heródoto escreveu que os trácios pensavam que a pele lisa significava falta de identidade. Elaboradas tatuagens eram consideradas marcas de beleza da nobreza para homens e mulheres na Trácia; até mesmo pessoas comuns tinham algumas pequenas tatuagens. Cerca de quatrocentos anos depois de Heródoto, o orador grego Dion Crisóstomo observou que mulheres trácias ainda se cobriam com tatuagens como marcas de alta posição social. Heródoto também descreveu tatuagens de citas-trácios falantes de língua iraniana, chamados de Agathyrsi. De acordo com uma história que ouviu em Ponto, os Agathyrsi se aclamavam descendentes de uma mulher cita com Héracles. Os Agathyrsi eram uma das tribos que expulsou Dário I da Pérsia (século VI a.C.). Mais tarde (século IV a.C.) eles migrariam para o norte, nas estepes sármatas. Especialmente as mulheres de Agathyrsi preferiam as tatuagens, como notou Heródoto. Quanto maior o status, maior o tamanho, mais detalhados e mais coloridos eram os desenhos em suas peles. Amiano Marcelino (século IV d.C.) relatou que as tatuagens dos Agathyrsi eram desenhos quadriculados em tinta preta azulada. ${ }^{12}$

Quando o general e historiador grego Xenofonte liderou seu exército por Ponto (cerca de 400 a.C.), a terra das amazonas, ele observou que a pele dos homens, mulheres e crianças da tribo Mossynoeci era coberta com tatuagens de flores coloridas. Pompônio Mela também relatou que tais pessoas marcavam completamente seus corpos com tatuagens. Os sármatas, extremamente associados às Amazonas, recebiam sua primeira tatuagem quando crianças, de acordo com Sexto Empírico e Plínio; Plínio também relatou que entre os sármatas, dácios e bretões, as mulheres "escreviam em seus próprios corpos." 13

${ }^{12}$ Hipócrates Ares, Águas, Lugares A, 26. Heródoto 5.6; 4.8-13. Dio Crisóstomo Oração 14.19. Amiano Marcelino 31.2; cf Pomponius Mela 2.1.10.

${ }^{13}$ Xenofonte Anabasis 5.4.32. Pomponius Mela 1.106. Plínio 22.2.2. Sexto Empírico 3.202.

Heródoto, Unifesp, Guarulhos, v.4, n.1 - 2019.1. p. 305-326

DOI: 10.34024/herodoto.2019.v4.10126 
Clearco de Soles declarou explicitamente que mulheres citas historicamente homólogas às amazonas - ensinavam a arte da tatuagem às mulheres trácias, que vivam nas fronteiras noroestes da Cítia. Filósofo grego que viajou e escreveu extensivamente sobre a Trácia e a Cítia (cerca de 320 a.C.), Clearco relatou que mulheres citas "costumavam decorar mulheres trácias em todo o corpo, usando fivelas (ou pinos de broche) como agulhas". Depois de muitas gerações, mulheres trácias começaram a adicionar seus próprios enfeites e outros desenhos aos temas citas. Relatos sobre tatuagens pelos trácios, citas, sármatas, Agathyrsi, Mossynoecians do Ponto, Illyrians, dácios, Geloni e Iaopodes são convincentes evidências que muitas das mulheres conhecidas como amazonas praticavam a tatuagem. ${ }^{14}$

Devido ao pensamento grego de que tatuagem eram marcas de degradação, ao invés de símbolos de nobreza, coragem e beleza, eles procuravam explicar o porquê de as mulheres optarem pela dor para decorar seus corpos com desenhos permanentes. Clearco sugeriu que as tatuagens foram inicialmente infligidas por violência pelas mulheres citas, e posteriormente incluídas pelas mulheres trácias, que habilmente transformaram tatuagens "vergonhosas" em encantadores ornamentos para o corpo. Os citas invadiram partes da Trácia se casando com os trácios e influenciando sua cultura. Tatuagens forçadas em cativos são certamente atestadas em tempos antigos e modernos. Mas compartilhar temas e técnicas entre as culturas também é bem conhecido. ${ }^{15}$ Qual foi o

\footnotetext{
${ }^{14}$ Clearco, da escola peripatética de Aristóteles, viajou até o Rio Oxus (Amu Darya) em Baktria (Afeganistão). Este relato de seu multivolume Vidas está preservado do final do segundo século a.C. Learned Banquet 12.27 (524 d, e.). A história de Clearco ocorre numa discussão da decadência das culturas citas e outras culturas bárbaras. Plutarco On the Delay od Divine Justice 12 repete a história de que homens trácios tatuaram suas esposas em vingança pela morte de Orfeu, mas essa racionalização reflete a noção grega de tatuagens como punição e contraria com relatos de que homens trácios usavam tatuagens e mulheres trácias eram representadas como já tatuadas quando mataram Orfeu. Tsiafakis 2000. Os túmulos citas oferecem ricasricas fivelas douradas, afulhas e pigmentos. Estrabão 4.6.10, 7.5.4, Iapodes e Trácios. Plínio 22.2.2. Amiano Marcelino 22.8; 31.2.14-17. Virgílio Eneida 4.136; Georgics 2.115. Claudian In Rufinus 1.313, Geloni da Cítia tatuou seus braços e pernas.

${ }^{15}$ Para relatos antigos similares de tatuagens infligidas e depois tidas com orgulho, e exemplo de tatuadores prisioneiros de guerra na antiguidade clássica, ver Mayor 1999. Relatos de como as tatuagens se originaram muitas vezes se referem anacronicamente à história mais recente e refletem a desaprovação moderna do que antes era considerado como marcas de beleza permanentes. De acordo com lendas croatas na Bósnia e Herzegovina, garotas tatuadas surgiram no início do Império Otomano (14001922) como proteção contra sequestros de turcos. O raciocínio tem um anel folclórico (a história na Burmânia, por exemplo, é de que garotas chinesas eram tatuadas para torna-las pouco atrativas para possíveis sequestradores). Em outras partes do Império Otomano, uma versão diferente é contada: turcos supostamente infligiam tatuagens em
}

Heródoto, Unifesp, Guarulhos, v.4, n.1 - 2019.1. p. 305-326

DOI: 10.34024/herodoto.2019.v4.10126 
contexto histórico do relato de Clearco? Mulheres citas alguma vez tatuaram cativas trácias? Ou elas simplesmente ensinaram suas vizinhas trácias como se tatuar? 16

Outras evidências literárias sobre costumes de se tatuar entre as culturas dos estepes, vêm de fontes distantes da Grécia. A confederação de nômades do extremo leste da Cítia (Ásia Menor) era conhecida pelos chineses como Xiongnu. Diversas fontes chinesas antigas descrevem as tatuagens como adornos entre os nômades "bárbaros" do norte ao oeste. Por exemplo, o Liji ("Registro de Ritos") do período dos Estados Combatentes e da Dinastia Han (475-87 a.C.) diz que essas tribos "selvagens" comiam a carne e usavam a pele de animais, e alguns tatuavam as testas. O Zhan Guo Ce ("Intrigas dos Estados Combatentes", do terceiro ao primeiro séculos a.C.) diz que os nômades ocidentais gravavam os ombros esquerdos com tatuagens. O Nan Shih ("História das Dinastias do Sul", cerca de 630 d.C.) relata a "Terra dos Tatuados", onde pessoas "não civilizadas" marcavam a si mesmos com listras e manchas como bestas selvagens; povos siberianos de estatura "gigante" usavam tatuagens significando coragem e estado civil. Muitas representações artísticas em sítios arqueológicos da Dinastia Han à Dinastia Shang (1500 a.C. - 220 d.C.) confirmam que o povo habitante do norte e oeste da China praticavam a tatuagem. ${ }^{17}$

Uma história de Han (Shiji, "Registros do Historiador" por Sima Qian, cerca de 147-85 a.C.) narra as negociações do imperador com a poderosa tribo de Xiongnu, que exercia constante pressão sobre a fronteira ocidental da China. Os nômades mantiveram a vantagem do quinto ao terceiro século a.C. recebendo preciosos presentes e princesas Han como esposas para selar tratados (ver capítulo 25). Os líderes nômades exigiam que os enviados chineses fossem tatuados (me [mo] ch'ing, "tatuagem em tinta preta") antes que pudessem se encontrar com o Shan-yu ("Maior", chefe). Os chineses, como os gregos, geralmente consideram a tatuagem como uma forma de punição. Entretanto, como na Grécia Antiga, linhas eram borradas entre vergonhosas, heroicas e belas tatuagens para os chineses, especialmente aquelas sobre os poderosos guerreiros nômades do oeste. Alguns enviados chineses, como Wang $\mathrm{Wu}$, um nortista

mulheres cristãs sequestradas. Outros relatos afirmam que as tatuagens começaram como "amuletos" protetores contra a peste na Era Bizantina. Durham 1928, Krutak 2010; praga: Meserve 1999, 175.

${ }^{16}$ Notadamente, Clearco usou a palavra positiva "decorar" para as tatuagens citas ao invés do verbo no negativo. Shapiro 1983, em Amazonas, Trácios e Citas.

17 Reed 2000, 7, 10-11, 17n38. Murphy 2003, 22. Lebedynsky 2010, 112. A primeira palavra chinesa para escrever, wén, refere-se à tatuagem (graças à Victor Mair).

Heródoto, Unifesp, Guarulhos, v.4, n.1 - 2019.1. p. 305-326

DOI: 10.34024/herodoto.2019.v4.10126 
familiarizado com os costumes dos Xiongnu, não teve dúvidas em cumprir as condições dos nômades. ${ }^{18}$

\section{Mulheres e tatuagens}

Tatuagens são frequentemente associadas às mulheres em muitos exemplos antigos e modernos. Homens trácios tatuados não são representados na arte grega, embora Heródoto, Xenofonte, Cícero e outros, incluíssem homens em suas descrições sobre tatuagens. ${ }^{19}$ Evidências arqueológicas sugerem que tatuagens em mulheres têm uma história extremamente antiga pela Trácia e pelo oeste da Cítia. Sítios neolíticos da cultura Cucuteni (4800-3000 a.C.) nas florestas das estepes da Romênia e no sudoeste da Ucrânia, têm rendido centenas de estatuetas femininas de barro inscritas com linhas e espirais; alguns estudiosos acreditam que sejam representações de tatuagens. Junto às estatuetas de barro, arqueólogos também desenterraram um esconderijo de falanges de cavalos com inscrições (ossos dos pés). O formato natural dos ossos sugere um torso feminino nu; os côndilos distais lembram seios ou ombros. Os ossos de quatro polegadas foram alisados e polidos, e em seguida inscritos com formas geométricas (por vezes mamilos eram indicados). Uma interpretação óbvia das decorações é de que elas significariam tatuagens. Estatuetas similares foram descobertas em sítios de mesma datação, próximas à Lykastia, em Ponto (região conhecida por mulheres guerreiras, de acordo com Apolônio de Rodes; capítulo 10). Padrões espirais também decoram estatuetas semelhantes do mesmo tempo no Turcomenistão. Ainda em outra região associada às amazonas Gobustão, no Azerbaijão, têm cerca de sete mil petróglifos antigos (Neolítico-Idade do Bronze) representando símbolos, animais e pessoas armadas com arcos, machados e lanças, algumas montando a cavalo. Uma composição mostra oito mulheres (carregando arcos?) cujas marcas no corpo podem indicar tatuagens. ${ }^{20}$

\footnotetext{
18 Xiongnu: Murphy 2003, 15-24; Linduff 2008, 175-81. "Missão para o oeste" em Han Shu 94A.3772 por Zhang Qian (Chang K'ien). Ambivalência chinesa sobre tatuagens: Reed 2000, 5-6n10, 47. Meserve 1989; Meserve 1999, 171-72. Watson 1962, 155-92.

19 Cícero De Off. 7.25, homens trácios tatuados. Herodian 3.14.7 sobre tatuagens geométricas e de animais, de celtas e pictos. David-Kimball 2002, 79, sugere que tatuar era uma arte feminina, baseado em pigmentos minerais encontrados em tumbas de mulheres; Linduff e Rubinson 2008, 21-22, 25; Mas pigmentos de tatuagens e agulhas foram encontrados em tumbas de homens, veja abaixo.

${ }^{20}$ Cultura cucuteni-trypillian, Anthony 2007; tatuagens, Lobell e Powell 2013. Gobustan é um UNESCO World Heritage Site. Ateshi 2011 e http://gobustan.si.edu/dating_methods_chronology.
} 


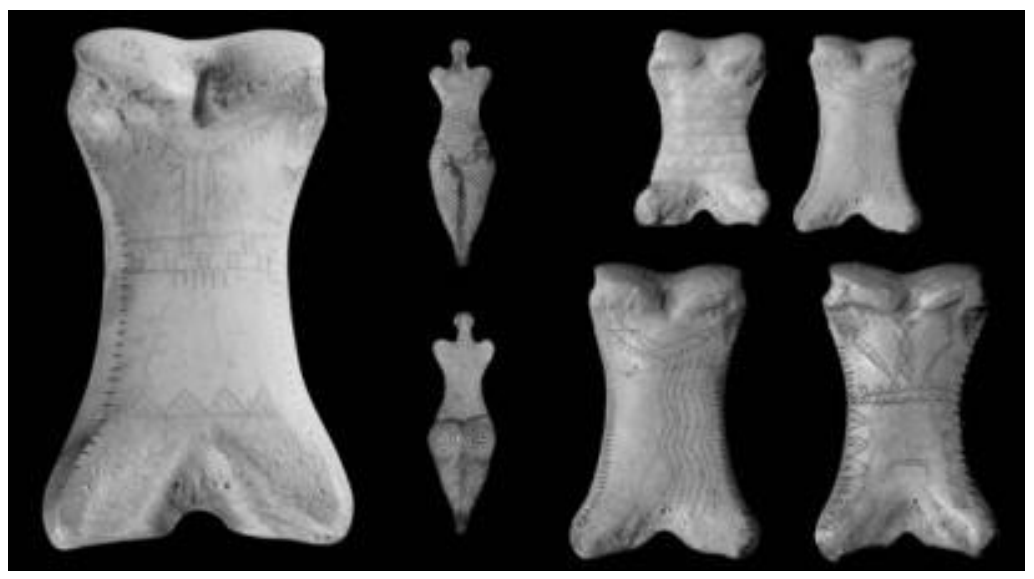

Figura 6: Formas femininas do neolítico, inscritas com desenhos que parecem tatuagens. Esquerda e direita, figuras de ossos de patas de cavalo, cultura Botai, Cazaquistão; Centro, cultura Cucuteni, figuras em barro, Ucrânia. Fotos cortesia de Sandra Olsen, montagem por Michele Angel.

A curiosa prática de criar torsos femininos decorados a partir de ossos de cavalos era muito difundida da Romênia e Ponto até o Cazaquistão, o coração da antiga Cítia. Depósitos destas formas femininas talhadas, junto à vastas coleções de remanescentes de cavalos, foram recentemente escavadas em sítios arqueológicos da cultura Botai do norte do Cazaquistão (cerca de 3700-3100 a.C.). Estes povos seminômades estavam entre os primeiros a domesticar os cavalos. Evidências arqueológicas também mostram crânios humanos em tigelas, leite de égua fermentado (koumiss; capítulo 9), e aparentemente gozavam de um alto nível de igualdade de gênero, características proeminentes da vida cita-amazona relatada por Heródoto e outros. ${ }^{21}$

Arqueólogos interpretam as marcações geométricas nas estatuetas de osso de cavalo botai como uma das mais antigas representações de construção de roupas. Baseados na suposição de que as marcas nos torsos indicam costuras, cintos e decotes, os arqueólogos sugerem que as cavaleiras botai vestiam vestidos de cânhamo rígidos e folgados até os tornozelos. Se as incisões nos torsos representam roupas, uma túnica ajustada ao corpo pode ser indicada, já que nada abaixo dos quadris é mostrado. (Saias largas podem ser modificadas em uma espécie de calça para andar a cavalo; veja abaixo e capítulo 12).

Uma possibilidade alternativa, não mencionada pelos arqueólogos, é que as linhas em alguns torsos femininos representam tatuagens. Como vimos, pode ser difícil distinguir tatuagens, ou pinturas corporais, de roupas em artefatos antigos. Os padrões botai que os arqueólogos interpretam como costuras, lembram as tatuagens de escadas/cercas que

${ }^{21}$ Olsen e Harding 2008. Anthony 2007, 216-24. Baumer 2012, 84.

Heródoto, Unifesp, Guarulhos, v.4, n.1 - 2019.1. p. 305-326

DOI: 10.34024/herodoto.2019.v4.10126 
imitam as costuras de mangas ao longo dos braços nus das mulheres trácias, nos vasos gregos. Padrões similares de costuras aparecem em estatuetas femininas nuas de barro do Turcomenistão (2600-2100 a.C.); elas também aparecem em braços tatuados de mulheres bósnias e curdas. ${ }^{22}$ A superfície deliberadamente alisada do osso de cavalo para fazer parecer mais como um torso feminino bem feito - por vezes com pontos na região pubiana ou mamilos - transmite a impressão de nudez. Se estes objetos possuem um propósito ritualístico, como argumentado por alguns arqueólogos, uma forma feminina nua parece mais apropriada e poderosa do que uma forma coberta. É interessante que os traços, ziguezagues, hachuras e escadas, triângulos e chevrons prefiguram padrões tanto nos exóticos trajes das amazonas, como nas tatuagens trácias das pinturas nos vasos. No mais, as misteriosas formas femininas criadas com ossos de cavalo apontam para uma antiga e forte relação entre cavalos e mulheres em terras trácias-citas.

Tradições de tatuagens entre mulheres persistem em diversos locais associados com às antigas amazonas, tanto míticas como históricas. Como nos Bálcãs, no Daguestão, entre o Cáucaso e o Mar Cáspio (onde a rainha amazona Marpésia foi atuante), mulheres continuavam a tatuar seus braços com símbolos geométricos. Suas tradicionais marcas incluíam pontos (mensagens amorosas codificadas), luas (para felicidade e sorte) e marcas de pássaros (pensado para tornar uma garota em uma rápida corredora). Tatuagens ornamentais também são praticadas por mulheres de Aghach Eris, nômades falantes de turco-persa do Irã, e pelos turcomenos. Mulheres curdas do norte do Iraque e do sul do Cáucaso que acreditavam ser descendentes dos hurritas, que falavam uma língua caucasiana, ainda se tatuavam com círculos listrados, meias luas, pontos, chevrons, cercas e formas de pentes. Em sua jornada pela Ásia Central no século XIII, Marco Polo descreveu como homens e mulheres usavam agulhas e tinta para gravar "estranhas semelhanças" com aves de rapina, leões e dragões em seus corpos. Em muitas culturas, desenhos de tatuagens são repetidos em roupas, tecidos e outros objetos, os quais ajudam a explicar a similaridade com os temas bárbaros em roupas e na pele de antigos trácios, citas e amazonas, na arte grega antiga. ${ }^{23}$

\footnotetext{
${ }^{22}$ Desenhos de costuras parecidas com "escadas" em mulheres trácias tatuadas, e.g. uma ânfora "nolana" do Pintor de Oinocles, ca. 470 a.C., Museu Britânico E 301, Cohen 2000, 107, fig 4.2; e uma hídria do Pintor de Egisto, ca. 470 a.C., Louvre 2587, Oakley 2000, 243, fig 9.9. Figuras do Turcomenistão, Baumer 2012, 65, 66; tatuagens, 134, 161, $186,189$.

${ }^{23}$ Chenciner, Ismailov, e Magomedkhanov 2006. Meserve 1999, 175; Meserve 1989, 219; Field 1958; Smeaton 1937; Izady 1992. Temas de tecidos e tatuagens, S. Pankova em Della Casa e Witt 2013.
}

Heródoto, Unifesp, Guarulhos, v.4, n.1 - 2019.1. p. 305-326

DOI: 10.34024/herodoto.2019.v4.10126 


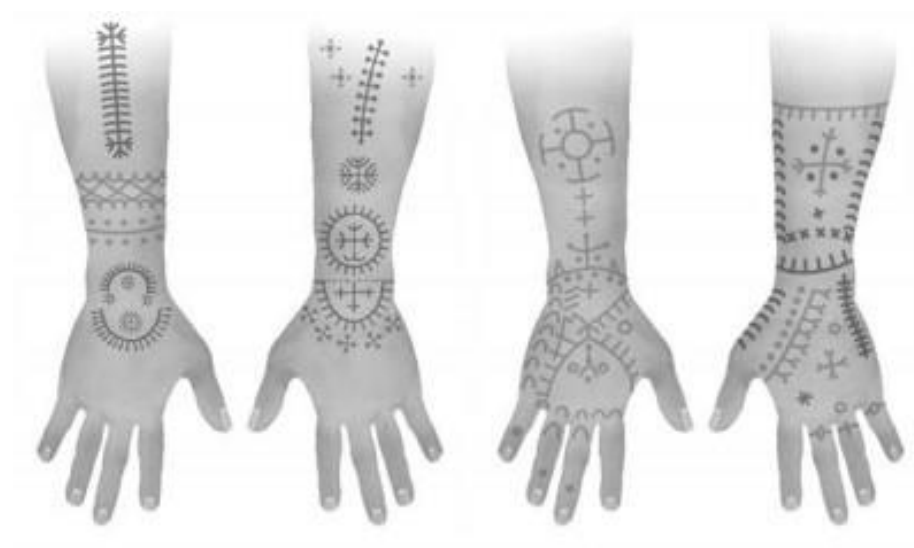

Figura 7: Tatuagens tradicionais em antebraços e mãos de mulheres bósnias (esquerda) e mulheres curdas (direita). Desenhado por Michele Angel.

Alguns estudiosos modernos argumentam que pintores de vasos atenienses desenhavam mulheres trácias para marca-las como "selvagens" que falharam em conformar-se ao ideal feminino grego. Da mesma maneira, o padrão exuberante em roupas vestidas pelas amazonas e pelas citas na arte grega, é pensado como uma convenção artística para sinalizar a "alteridade". Mas as tatuagens artisticamente realizadas em vasos gregos eram fundamentadas em fatos: já que tatuagens eram vistas diariamente em Atenas. As formas específicas das tatuagens trácias repetidas em padrões usados pelas amazonas - não eram simplesmente inventadas por artistas gregos em oficinas de cerâmica. Os mesmos desenhos abstratos de animais aparecem em couro, madeira e objetos de ouro escavados em tumbas trácias e citas, por volta de 550-100 a.C., que também combinavam tatuagens com temas tradicionais em habitantes outrora vivos em antigos territórios amazônicos. ${ }^{24}$

Os métodos e temas de tatuagens são extraordinariamente conservadores e inalterados por milênios (agulhas, pigmentos e estêncils foram descobertos em tumbas citas). Primeiro o desenho era desenhado ou traçado na pele. Um agrupamento de três ou sete agulhas perfuravam o desenho na pele e o pigmento era esfregado (pasta de carbono de cinzas de carvão). A pasta era diversamente misturada com outras substâncias, como seiva, mel, suco de frutos silvestres ou índigo (um pigmento azul), seiva, bile de boi (para definir o corante), saliva, ou o leite materno de uma mulher amamentando uma bebê do sexo feminino ou, nos Balcãs, de

${ }^{24}$ Tecidos citas: Polosmak 2003, Rolle 1989, 95-98; Barber 1991; Phoenix e Arabeth 1999; Han 2008, 50 fig 3; Murphy 2003, 5: roupas de lã em túmulos citas, quatro cores, decorações triangulares e romboide; Wagner et al. 2009; Barber 2000.

Heródoto, Unifesp, Guarulhos, v.4, n.1 - 2019.1. p. 305-326

DOI: 10.34024/herodoto.2019.v4.10126 
um menino. As tatuagens coloridas de flores dos Mossynoeci de Ponto, sugerem que os pigmentos coloridos eram conhecidos na antiguidade. ${ }^{25}$

Recentemente, em 2013, equipamentos de tatuagem foram escavados próximos à um esqueleto vestido em uma túnica ricamente decorada, e calças, enterrado com objetos luxuosos num kurgan sármata-cita nos estepes entre os Montes Urais e o Mar Cáspio. O kit de tatuagem consiste em pigmentos e colheres para mistura-los em duas paletas de pedra, agulhas de ferro douradas e outras ferramentas. Muitos sepultamentos citas contém itens similares que foram confundidos com cosméticos femininos por arqueólogos anteriores. ${ }^{26}$

Abundantes evidências tornam seguro assumir que os gregos eram familiarizados com as práticas de tatuagem da Cítia e de tribos relacionadas à Eurásia, e que esperariam que as mulheres conhecidas por amazonas usassem desenhos com tinta. A mais poderosa prova está congelada no tempo - inscrita na pele de corpos mumificados recuperados de geladas sepulturas em Altai. Graças às extraordinárias descobertas recentes, agora sabemos que tipo de tatuagens foram utilizadas por verdadeiras cavaleiras nos estepes.

\section{Tatuagens de múmias congeladas da antiga cítia}

Em 2003, no laboratório científico do Museu Hermitage em São Petersburgo, arqueólogos observaram atentamente os raios infravermelhos aplicados nos corpos mumificados de homens e mulheres citas da época de Heródoto. Invisíveis ao olho nu até o momento, imagens de cervos e desenhos de outros animais pareciam surgir magicamente sobre a pele. $\mathrm{O}$ pigmento de carvão desbotado de excepcional qualidade, e elaboradas tatuagens se tornaram visíveis sob a luz infravermelha, permitindo aos arqueólogos russos L. L. Barkova e Svetlana Pankova fotografar pela primeira vez um impressionante número de tatuagens anteriormente escondidas. Característica da antiga arte cita de "estilo animal", as imagens das peles recém-descobertas incluem cervos, alces, cavalos, ovelhas montesas (argali), tigres, leopardos, pássaros e criaturas imaginárias com bicos, asas e fantásticos chifres. Os desenhos foram espetados na pele com agulhas e depois esfregados com fuligem. Acredita-se que os tatuadores citas foram os primeiros a usar estênceis de transferência - um estêncil de couro recortado de uma tatuagem de carneiro de uma das múmias foi

25 Truhelka 1896; Krutak 2010; Field 1958, Durham 1928. Rudenko 1970, 112. Seda com fio carregado de fuligem: Meserve 1999, 181n2; Mayor 1999; stencils, Phoenix e Arabeth 1999. Tatuagens coloridas do século IX China: Reed 2000.

${ }^{26}$ Yablonsky 2013.

Heródoto, Unifesp, Guarulhos, v.4, n.1 - 2019.1. p. 305-326

DOI: 10.34024/herodoto.2019.v4.10126 
encontrado em seu túmulo. Muitas das figuras de animais foram cuidadosamente colocadas no corpo para dar um efeito ondulante quando a pessoa se movesse ou flexionasse seus músculos.

As estepes de Altai abrangem partes da Rússia, Cazaquistão, China, Mongólia e a República de Altai. A vasta região está repleta de kurgos de povos nômades intimamente relacionados aos grupos saka, sármata e cita que costumavam percorrer as vastas altas planícies entre o Mar Negro e a Mongólia. 27 Os corpos das duas mulheres e dos dois homens armazenados no Museu Hermitage foram enterrados com tesouros de ouro e cavalos sacrificados dos séculos V ao III a.C. Seus corpos foram preservados inteiramente intactos pelo pergelissolo (camada de solo congeleada) do Vale Pazyryk ("Monte"), na Rússia. Quando os primeiros túmulos da cultura pazyryk foram escavados em 1947-49 por Sergei Rudenko, as extensas tatuagens de animais de apenas um guerreiro (o famoso "chefe tatuado de pazyryk" no segundo monte) eram visíveis. A câmera infravermelha captou uma nova tatuagem de um galo em seu dedo. Outra múmia congelada da tardia cultura de Tashtyk, do século I d.C., havia sido escavada em 1969 em Khakasia, ao norte. Ele também era muito tatuado com meias luas, rosetas, arco e flecha e grandes figuras não identificáveis. ${ }^{28}$

Uma das mulheres pazyryk tinha em torno de quarenta anos quando foi enterrada ao lado do chefe tatuado no segundo monte. Mais de dois milênios depois de sua morte, a câmera infravermelha revelou que ela também estava intrinsecamente tatuada. Em seu ombro há um fantástico cervo torcido. Ele possui um bico de grifo e galhadas pretas com dentes em forma de cabeça de grifo (um tema visto em artefatos trácios e citas). Em seu outro ombro há uma ovelha da montanha contorcida. Um desenho realista de chifres de cervo circunda seu pulso.

A outra mulher, com cerca de cinquenta anos, foi enterrada na quinta montanha com um homem de cerca de cinquenta e cinco. Graças à tecnologia, agora podemos finalmente ver suas finas tatuagens. $\mathrm{O}$ corpo do homem está excessivamente tatuado com pássaros, dois cavalos com rostos expressivos, cinco cervos, três ovelhas e um enorme tigre furioso envolvendo seu ombro esquerdo e seu peito. Os braços e mãos da mulher

\footnotetext{
${ }^{27}$ Citas dos estepes Altai: Han 2008.

28 "Descobertas de tatuagens" 2005. Rudenko 1970, 110-14, 247-66. Barkova e Pankova 2005. Tatuagens tashtyk são evidentes em máscaras de gesso entre os bens enterrados e os temas estão repetidos em seus tecidos: Pankova em Della Casa e Witt 201; Baumer 2012, 171; Achados pazyryk, 186-92. Tumbas "citas" comparadas com Heródoto: Ivantchik 2011, tatuagens, 92.
}

Heródoto, Unifesp, Guarulhos, v.4, n.1 - 2019.1. p. 305-326

DOI: 10.34024/herodoto.2019.v4.10126 
estão cobertos de tatuagens. Em seu antebraço esquerdo, uma enorme ave de rapina ataca um cervo que está lutando. Em seu antebraço direito, uma elegante tatuagem retrata um leopardo e dois tigres-do-cáspio atacando um veado e um alce malhado, ou um gamo com largos chifres (o habitat do tigre-do-cáspio se estende desde o Cáucaso até o Altai). Os arqueólogos acreditam que esta complexa composição de "cartelas" demonstram uma influência chinesa. Seda e artefatos chineses foram encontrados em diversas Altai de Kurgan, demonstrando troca e quiçá alianças matrimoniais com a China; bens enterrados em túmulos pazyryk vieram da China, Índia e Irã. ${ }^{29}$

Os arqueólogos do Museu Hermitage ficaram encantados ao descobrir que tais mulheres dos estepes eram tatuadas. Eles seguiram um palpite baseado nas escavações de Rudenko em 1947 do chefe tatuado e de outros notáveis corpos, em 1993, na região do Altai. Naquele ano, a arqueóloga russa Natalya Polosmak desenterrou a emocionante descoberta de um luxuoso túmulo, não saqueado, de uma sexta múmia congelada por dois mil e quinhentos anos.

Com a ajuda de alguns soldados russos parados no solitário posto avançado no alto planalto de Ukok (7.500 pés), Polosmak e sua equipe escavaram um grande cerca de arame farfado de Kurga de exatamente dez metros que demarcava uma "terra-de-ninguém" na fronteira com a China. Depois de duas semanas cavando o monte daquela primavera nevada, eles encontraram um caixão de madeira de lariço decorado com grandes recortes de couro de cervo. Erguendo as quatro unhas de cobre que prendiam a tampa, encontraram um bloco de gelo dentro. A equipe cuidadosamente colocou copos d'água quente sobre o caixão. Por fim, surgiu um ombro coberto de pelo de marta (zibelina). Polosmak levantou a pele e viu "uma brilhante tatuagem azul de uma magnífica criatura parecida com um grifo" na pele da mulher. Polosmak identificou a "Princesa do Gelo" como "uma das múmias amazônicas" da cultura pazyryk. ${ }^{30}$

${ }^{29}$ Barkova e Pankova 2005. O kurgan pazyryk estava saqueado na antiguidade, nenhuma arma foi encontrada nos montes 2 e 5. Itens trocados: Baumer 2012, 187-91.

${ }^{30}$ Polosmak 1994. Bukker 2011. Princesa do Gelo, kurgan Ak-Alakha 3, monte 1.

Heródoto, Unifesp, Guarulhos, v.4, n.1 - 2019.1. p. 305-326

DOI: 10.34024/herodoto.2019.v4.10126 


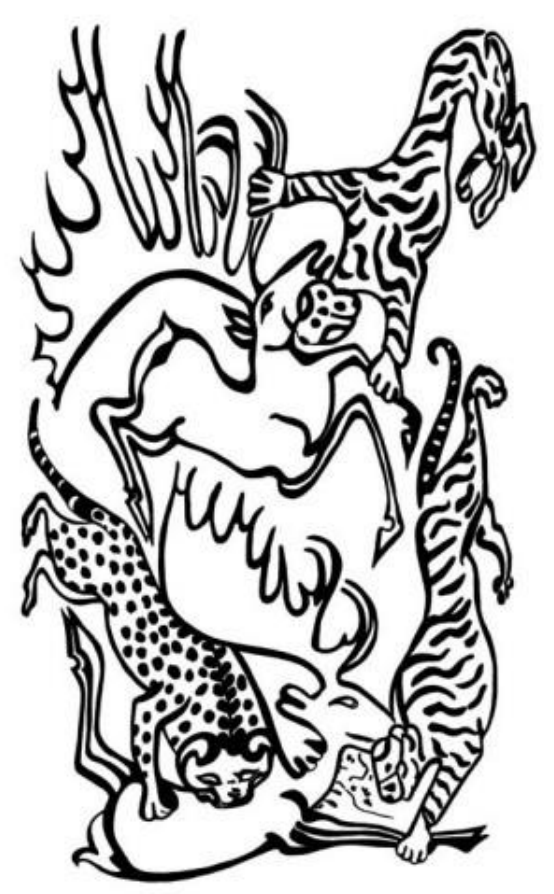

Figura 8: Cartela de tatuagem de um leopardo e dois tigres atacando um veado e um alce, no braço de uma múmia feminina congelada, revelado por câmera infravermelha, monte 5, Pazyryk, quinto ao terceiro séculos a.C. Desenhado por permissão, cortesia de Svetlana Pankova; de Barkova e Pankova 2005, fig. 14.

Uma alta cavaleira $(167 \mathrm{~cm})$ com aproximadamente vinte e cinco anos quando faleceu, em torno de 500 a.C. Seus seis cavalos castanhos com deslumbrantes rédeas douradas haviam sido sacrificados e enterrados ao redor dela. Ela usava elaborados brincos, uma túnica de seda amarela e marrom, um imponente cocar enfeitado com veados e cisnes, botas de feltro e pele bordadas até a coxa e uma larga saia de lã vermelha que podia ser levantada para andar a cavalo por um cinto vermelho trançado. Análises de suas roupas mostraram que sua túnica chinesa era feita de seda selvagem indiana e que os corantes eram originários do leste do mediterrâneo ou do Irã. Os exóticos bens mostram que a cultura pazyryk "tinha amplas e extraordinárias conexões com a China, Índia, Irã e com o Mediterrâneo". Para sua jornada após a vida, ela estava acompanhada por uma tigela de leite de égua fermentado (koumiss), um prato de madeira para carnes com uma faca de bronze, e seus objetos de uso diário, incluindo um pequeno espelho com um cervo gravado atrás. ${ }^{31}$

${ }^{31}$ Polosmak 1994; Molodin 1995 (múmias de homens tatuados de Ukok). "Princesa Siberiana" 2012. "Segredos de moda e beleza" 2012. A Princesa do Gelo retornou à República de Altai em 2012, onde está em um sarcófago de vidro no Museu Nacional Republicano. Trocas citas com a China e Índia, Stark et al. 2012, 121-38, “Tribos perdidas" 2013.

Heródoto, Unifesp, Guarulhos, v.4, n.1 - 2019.1. p. 305-326

DOI: 10.34024/herodoto.2019.v4.10126 
Cavalos, cervos e grandes felinos eram animais extremamente importantes para os povos citas. Seu estilo artístico único frequentemente apresentava cervos com corpos torcidos e exagerados chifres ramificados. (Eles enfeitavam até mesmo seus cavalos com chifres). $\mathrm{O}$ ombro da Princesa de Gelo foi decorado com um grande cervo retorcido com um bico de grifo e com extravagantes chifres estilizados, cada ponto terminando na cabeça de um grifo (muito semelhante às tatuagens da mulher pazyryk). Seus braços foram decorados com uma ovelha da montanha e uma pantera malhada ou um leopardo da neve. Outra cabeça de cervo com chifres ornamentados envolve seus pulsos como a "pulseira de chifres" na mulher pazyryk abaixo. Dois homens enterrados nas proximidades tinham tatuagens de cervo semelhantes em seus ombros e peitos. Cervos com chifres também são proeminentes em petróglifos e "pedras dos cervos" esculpidas, encontradas da Mongólia ao Mar Negro (capítulo 14). ${ }^{32}$

Para sociedades orais, como os citas, as tatuagens poderiam codificar ideias mitológicas e histórias tradicionais. Os belos animais estilizados e desenhados são certamente decorativos, mas provavelmente possuíam profundos significados para os indivíduos da tribo. Tatuagens podem ser vistas como uma linguagem viva escrita no corpo, uma forma de comunicação inscrita. Cada cena e animal pintados existiram dentro de um repertório de histórias comumente mantidas, enquanto detalhes específicos poderiam se referir à experiências pessoais (como caçadas bem sucedidas, ritos de passagem, sonhos) das pessoas tatuadas. Talvez indivíduos extremamente tatuados fossem contadores de histórias ou xamãs cuja arte corporal servisse de ilustração para narrativas culturais. Relatos gregos descrevem os citas totalmente vestidos, nunca nus ou seminus em público (ao contrário dos gregos). Muitos pintores de vasos enfatizaram isso ao retratar amazonas vestidas com mangas compridas e leggings lutando contra guerreiros gregos nus. Como suas dramáticas tatuagens não seriam normalmente observadas por inimigos ou estrangeiros, o arqueólogo russo Sergey Yatsenko sugere que as tatuagens citas eram "armas espirituais" e protetores mágicos particulares..$^{33}$

\footnotetext{
32 Pedras de cervos, Murphy 2003, 12; petróglifos de cervos, Stark et al. 2012, 65-66.

33 Princesa do Gelo como contadora de histórias ou xamã: "Princesa Siberiana" 2012; tatuagens como narrativas: "Múmias Tatuadas" 2012 (entrevista televisiva de Pankova). Ver Marazov 2011b, 134-38, na arte, e supostas tatuagens como “linguagem principal para recordar ideias mitológicas" em artefatos trácios. Tatuagens de símbolos abstratos podem ter sido uma forma de "escrita", com semelhanças com tamgas, ver capítulo 14 sobre linguagem. Sergey Yatsenko citado em Lobell and Powell 2013.
}

Heródoto, Unifesp, Guarulhos, v.4, n.1 - 2019.1. p. 305-326

DOI: 10.34024/herodoto.2019.v4.10126 
Evidências de costumes de tatuagens ainda mais antigos vieram à tona no norte da China. No deserto de Taklamakan, e em outros locais da bacia de Tarim ao longo da Rota da Seda, numerosas múmias de homens de mulheres foram naturalmente desidratadas na areia por aproximadamente três mil anos. Suas culturas e origens são misteriosas, mas seus corpos extremamente bem preservados estão tatuados com formas geométricas que se repetem em suas roupas de seda estampadas, ainda brilhantes e coloridas depois de muitos séculos. ${ }^{34}$

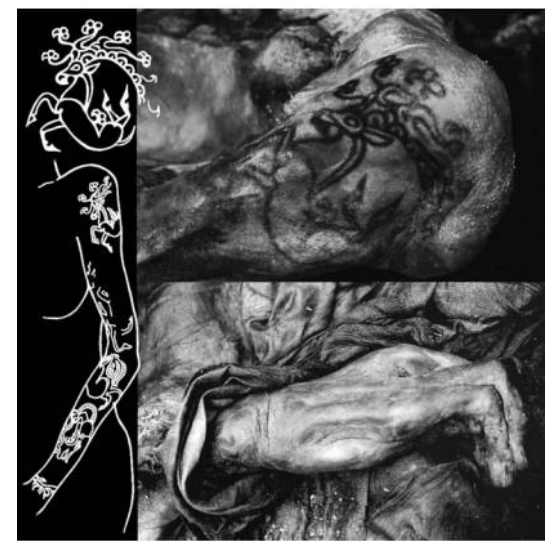

Figura 9: Tatuagens da "Princesa de Gelo", descoberta por Natalya Polosmak, Plato Ukok, quarto século a.C. Imagens cortesia de Svetlana Pankova, Museu Hermitage, S. Petersburgo.

Múmias são raras; elas dependem de condições muito especiais mantidas dentro de câmaras funerárias durante milênios. ${ }^{35}$ Os ocupantes mais comuns das tumbas de nômades dos estepes são meros esqueletos. No entanto, até mesmo os esqueletos podem revelar evidências de tatuagens entre os citas. $\mathrm{O}$ exemplo mais surpreendente é a figura de uma cobra impressa no osso da canela de um nômade da Idade do Bronze que foi enterrado perto do Mar de Azov. A tatuagem de carvão inserida na pele foi transferida para o osso da canela durante a decomposição do corpo. Um exemplo mais horripilante vem de um antigo texto chinês afirmando que traços de tatuagens poderiam ser identificados nos crânios ou nos ossos das canelas dos mortos. De fato, a exame por Sergei Rudenko da múmia pazyryk tatuada mostrou que as agulhas penetraram profundamente no músculo. 36

\footnotetext{
${ }^{34}$ Mallory e Mair, 2008; Barber 2000: 67, 130.

35 Aquecimento global, derretimento do gelo, assim como pilhagem e as estradas modernas ameaçando a preservação das múmias de Altai: Gheyle 2006; Han 2008.

${ }^{36}$ Natalia Shishlina, em Della Casa e Witt 2013. Reed 2000, citando entrada de tatuagens 285-86 de Duan Chengshi, Youyang zazu (cerca de 800-863 d.C.), 30.
}

Heródoto, Unifesp, Guarulhos, v.4, n.1 - 2019.1. p. 305-326

DOI: 10.34024/herodoto.2019.v4.10126 
As múmias de Altai e Tarim são provas tangíveis de tatuagens entre os povos nômades intimamente relacionados com os grupos identificados como citas e amazonas por seus contemporâneos, os antigos gregos. Os temas comuns de cervos nas mulheres trácias e nas mangas e calças das amazonas em diversas pinturas de vasos gregos são impressionantes. Os pintores dos vasos reproduziram precisamente os desenhos e animais preferidos por verdadeiros citas para decorar suas peles, tecidos e outras posses. Se a Princesa de Gelo e suas companheiras pudessem observar as pinturas nos vasos de mulheres trácias e amazonas, elas reconheceriam as tatuagens de cervos como miniaturas decorativas de si mesmas. Enquanto observadores gregos dos vasos poderiam se perguntar se as marcas exóticas nos braços e pernas das amazonas eram parte de sua roupa colada à pele ou se estavam inscritas em sua pele nua. Eles poderiam até mesmo conceber ambas as opções, imaginando que o tecido estampado escondia a pele estampada. 